\title{
The Status of Assessment Literacy and Classroom Practice of Secondary Level Teachers
}

\author{
Sarala Luitel \\ Sarala.luitel@cded.tu.edu.np \\ Lecturer \\ Central Department of Education, T.U., Kirtipur
}

\begin{abstract}
Assessment is the tool that measures the quality of education. This study was focused on the status of teachers' assessment literacy and practice in the classroom. A case study of a mixed research approach was conducted within the Kathmandu Valley selecting three schools. The questionnaire, Interview schedule, and observation checklist were the main tools. There were 27 teachers teaching fundamental subjects (Mathematics, English, Science, and Social Study) at grades $I X$ and $X$ were chosen for the survey and one mathematics teacher from each school was selected for interview. Two schools were selected for the observation. The constructivist theory was used to justify the finding. The result showed the high literacy status of the teachers with mean $2.63>2$ where $93.83 \%$ of teachers were known about the 18 different assessment techniques but only $66.26 \%$ of teachers apply those techniques in the classroom for assessment.
\end{abstract}

Keywords: Reflective, Literacy status, Assessment techniques, Formative assessment

\section{Introduction}

Teachers are the backbone of quality education as they can influence the standard of learning through their knowledge, belief, and practices (Buckman, 2007). Learners' standards can be observed based on their achievements in the examinations as well as in their learning behavior. However, assessment techniques that teachers utilize in their respective teaching and learning contexts are to be reliable and valid (Niss, 1993). In learning mathematics, including all other subjects, assessment should be focused to make instruction more responsive to students' needs and ensure that every student is gaining Mathematical power (National Council of Teachers of Mathematics, 1995) to transfer their knowledge to new situations for solving the problems they face in their respective real-life contexts (Khaniya, Parajuli, \& Nakarmi, 2015). For this, assessment should be able to assess their higher-order cognitive skills such as problem-solving, critical thinking, entrepreneurship, and creativity. Mellati and Khademi (2018) had researched 'Exploring Teachers' Assessment Literacy: Impact on Learners' Writing Achievements and Implications for Teacher Development. The results of the study demonstrated that instructors' assessment literacy has a significant impact on learners' writing ability. The findings also confirmed that there is a great difference between classroom practices of assessment literate instructors and assessment illiterate instructors. 
Poudel and Bhattarai (2018) had expressed that the national SSDP plan has provoked for monitoring and evaluation in the form of 'assessment for learning' instead of 'assessment of learning' clearly. This SSDP aim cannot be fulfilled without teachers' efficiency in the assessment sectors and similarly, the school environment also has to be supportive to increase and apply teachers' efficiency in the classroom. Therefore, this study is focused to elicit the status of teachers' assessment literacy and practices on assessing students' overall learning.

\section{Assessment Literacy: Concepts and situations}

Assessment is an integrated part of the teaching-learning activities. It is taken as a systematic process that provides an opportunity for teachers to meaningfully reflect on how learning is best delivered, collect respective evidences, and then use that information to improve their teaching (Kalajahi \& Abdullah, 2016). No factor is more important than the teacher to achieve the vision for school mathematics (Koellner et al., 2007). A teacher requires a sound knowledge of subject content, principles, and strategies, needs to believe in the potential of the subject and the learners should maintain a positive vibe as well. It is also the teacher who is to enthuses and motivates the learners about mathematics and the role it plays in their lives (Botha, 2011).

The term "Assessment literacy" is a broad term that has evolved in definition over the past threefour decades (Mellati \& Khademi, 2018). Assessment literacy was originally conceptualized as a practical professional skill and initially regarded as teachers' technical knowledge and skills. Developing assessment literacy among educators and leaders has been an unmet challenge for more than 50 years (Looney, Cumming, van Der Kleij, \& Harris, 2018). Since the turn of the 21 st century, developing teachers' assessment literacy has been recognized as one of the key levers for improving instructional practice and student learning in light of the education reforms worldwide. As we approach the third decade of the 21 st century, developing teachers' assessment literacy needs to be more responsive to the need of both pre-service and in-service teachers who come from linguistically and culturally diverse backgrounds (Koh, DePass, \& Steel, 2019).

Assessment literacy is not related to only the aspect of students' evaluation but overall system improvement. The concept of assessment literacy is defined as "the knowledge about how to assess what students know and can do, interpret the results of those assessments, and apply the results to improve student learning and program effectiveness" (Webb, 2002, p. 1). This definition of assessment literacy also can apply to the interpretation of results from both classroom and large-scale assessments. The challenges of making use of assessment results span both classroom assessment results and large-scale assessment results. Many barriers to assessment literacy appear due to outdated methods and practices. In a webinar Report, Marion and Shepard (2017) state that the knowledge and skills associated with designing, selecting, interpreting, and using high-quality assessments to improve student learning and serve other important educational and policy purposes.

Teacher assessment literacy is an emerging issue in education, as teachers are playing an increasingly central role in classroom assessment. In classroom assessment, teachers not only need to design and implement assessment tasks, but also need to interpret and communicate assessment results to their administrators, colleagues, students, and parents. The series of tasks 
requires teachers to make important yet complex professional decisions about assessment appropriate to their dynamic, situated contexts.

\section{Objectives of the Study}

This study is focused to

- elicit the status of teachers' assessment literacy.

- Analyze assessment practices assessing students' for overall learning.

\section{Methodology}

This is a case study research design adopting a mixed research approach (Gillham, 2000) believing on pragmatic world view (Creswell, 2002) that guides the inquirer, and in the case of mixed methods there may be one world view or multiple world views that appears to confirm, cross-validate, or corroborate findings within a single study (p. 26). This study was conducted within the area of Kathmandu valley. Three schools were selected from the best-awarded schools in the Secondary Education Examination (SEE) 2018 by the Ministry of Education for both community and institutional schools. Best schools were selected based on the number of students registered in class nine and the achievement level of SEE (Ministry of Education, Science, and Technology (MoEST, 2018).

The major tools for the data collection were questionnaires, interview schedules, and classroom observation memos. Sample for the study was assumed for both quantitative and qualitative nature of data where for the quantitative inquiry, teachers teaching four fundamental subjects; Mathematics ( 8 teachers), Science ( 7 teachers), English (6 teachers), and social study (6 teachers) from three case schools at the secondary level (IX \& X) altogether 27 teachers were there. For the qualitative inquiry, one mathematics teacher teaching in grade IX from each school was selected randomly for interview. Head teacher or Coordinator (in absence of the Head teacher) from all three schools was also considered as the interviewee to know the schools' or administrative plan for the teachers' professional development and practices of the assessment system. There were three schools altogether where one was community and two were institutional schools. But I have selected only two schools; one community and another institutional school because the next institutional school did not feel comfortable allowing the class observation. Therefore, I had selected only two schools for the class observation.

Mathematics class was observed for class IX in both selected schools; one community and another institutional school. Primary data were collected appearing researcher herself and descriptive statistics that are mean, standard deviation, and percentage were used to analyze the collected data. Similarly, I had used supportive theory 'the theory of scaffolding, for the validation of the data analysis to draw the finding and the conclusion. Quantitative findings were drawn based on the mean value calculated from the value provided by the participants on the scale of the questionnaire. After calculation of the mean based on the response provided by the respondent is more than 2 (scale mean), then the decision was taken the as high status of literacy level and practice level for the teachers otherwise the literacy level and practice level were taken as low status. 
This study specially benefits for the policy makers for the plan of professional development and to run assessments in a authentic way in a similar manner. Teachers can also be benefited by the work reflection as well as rethink regarding the assessment practice.

\section{Result}

The overall study findings regarding teachers' literacy and classroom practice status were high with the evidence of total response mean 2.63 which is more than the scale means of 2 along with the standard deviation of 0.44 . The status of teachers' literacy and practice has been analyzed under the respective sub-topics

Teachers' literacy status on assessments. There were 18 statements altogether for assessment techniques responded by the 27 teachers. The total percentage of teachers' literacy status is in the scale of 'I know there was $93.83 \%$ and teachers' response on the scale 'I don't know was $4.32 \%$ where the remaining data were missing. The result indicated that the overall status of teachers' literacy level was high status which can observe in the following Figure 1. In Figure 1 , the number of respondents is displayed on top of the bar diagram according to the response frequencies on different assessment techniques where the total number of respondents were 27 from all the four fundamental subjects Mathematics, Science, Social Study, and English.

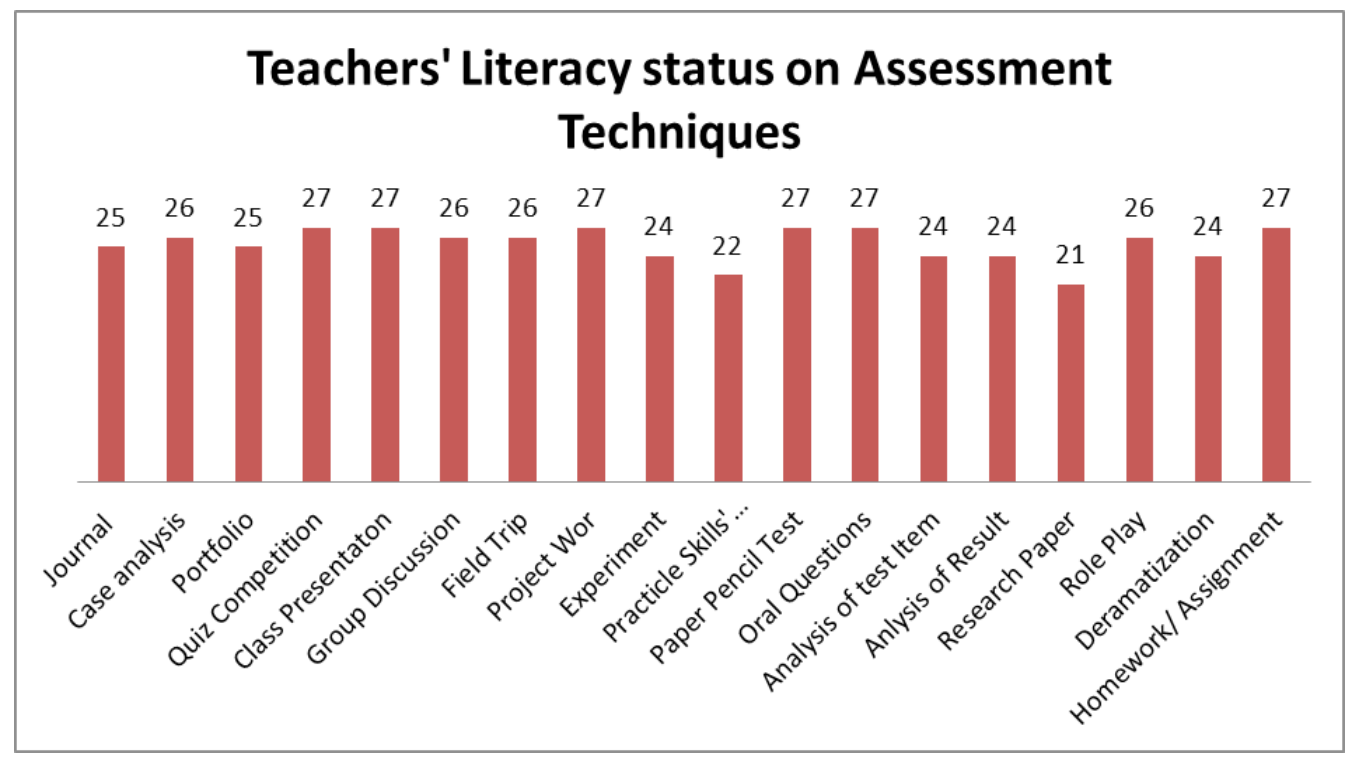

Figure 1 Teacher Literacy Assessment

Comparing the teachers' responses to different assessment techniques, there is a high mean score regarding the teachers' responses for all assessment techniques but just one assessment technique, 'research paper' had got less response (mean 1.96<2) from teachers. The average percentage of teachers' responses on the 'I know, I use' scale was $66.26 \%$, and 'I know, I don't use' was $27.57 \%$, both scales showed teachers have the knowledge about given assessment techniques so that the total percentage of teachers' knowledge i-e assessment literacy was $93.83 \%$ and teachers' response on the scale 'I don't know was $4.32 \%$. This result indicated that the overall 
status of teachers' literacy was high and there were fewer variations in teachers' responses due to the result based on standard Deviation 0.44.

The classroom practice status of teachers. The mean comparison between the response mean and the scale mean shows the high status for overall data that is $2.63>2$ but particular data also indicated the high status of the practice of a variety of assessment techniques in the classroom. The data has shown in the scale 'I know, I use' and 'I know, I don't use' was $66.26 \%$ and $27.57 \%$ respectively. These results directed that $27.57 \%$ of teachers did not use different assessment techniques in the classroom though they know. The following figure also shares the idea of teachers' assessment practices in the classroom on different assessment techniques where figure 2 is displayed based on teachers' numbers; there were 27 teachers all together as the respondents.

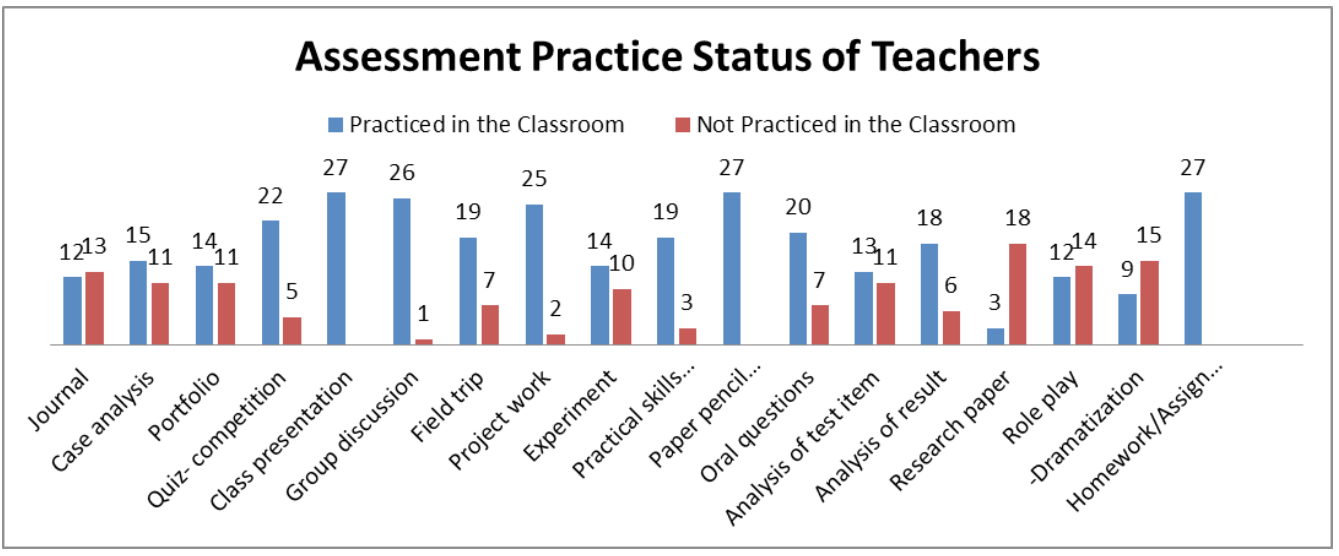

Figure 2: Status of Assessment Practice

When I go through the individual assessment techniques practiced in the classroom, I had found different scenarios. All 27 teachers (100\%) used these three assessment techniques; Paper pencil test, class presentation, and homework/assignment. Except for these three techniques, very few (less than 27) teachers used the remaining assessment techniques according to Figure 2. Preparation of the research paper is less practiced that is just $3(11.1 \%)$ assessment techniques among all other assessment techniques that can be seen in figure 2 above.

The interview was conducted with the mathematics teachers and practice was observed in the Mathematics classroom of class IX. Similarly, Head teachers were interviewed for the school policy regarding the assessment from three schools. From the interview data, teachers were agreed on the use of a variety of assessment techniques that can assess the different learning aspects, for example, knowledge and understanding level of learners, application skills according to the context, communication skill and way of presentation of content etc. but for mathematics students, written examination is enough generally. A community school teacher said "Mostly, the written examinations is enough to measure the students' knowledge but it does not measure other aspects like communication, presentation, and sharing, collaboration...these needs group work, project work, case analysis, etc." In the case of using different assessment techniques, institutional school teachers said, "School authority encourages using written 
examinations rather other assessment techniques and we follow the school calendar there is not mentioned such assessment techniques". Teachers were not free to use their assessment idea in the classroom due to different reasons; large class, school authority, and main reason evaluation system because there is no space for formative evaluation for formal examination system. A teacher expressed, "Authority believes on students marks got in test paper only. They expect high marks in a written examination rather the understanding of the students so better to make more practice for the examination preparation". This verbatim also directs the rigid form of assessment techniques used for evaluation formally but some teachers said they used to use many techniques in the classroom for the learning enhancement rather than evaluation process for the decision. Head teachers of the school also accepted that there is no planned policy for the formative evaluation, especially for Mathematics. They think the written examination is the most useful for mathematics than other assessment techniques.

The class observation result also supported the same result from the interview as they had practiced group discussion, classroom presentation, and project work for practical skill development though it was used very often. From the class observation, I had found the community school had adopted more assessment techniques to evaluate the learning status of learners in comparison to institutional schools they focused on written examination as a major assessment tool.

\section{Discussion}

There were 18 different assessment techniques chosen for the study. We can observe many techniques among them are being used in the classroom in our context. Different 18 techniques used for the survey were distributed under four sub-themes; Reflection, Practical assessment, Examination/test, and synthesis/analysis. The discussion has been organized based on these subthemes.

Reflection. Reflection focus to develop the capacity for self-assessment, reflective and selfdirected learning. In this theme, there were listed six different types of assessment techniques that help to assess the learners' ability on reflection they are; Journal, Case analysis, Portfolio, Quiz competition, Class presentation, and Group discussion. Among those entire techniques, observation data informed that mostly classroom presentation, group discussion, Portfolio, and quiz competition were practiced but journal and case analysis had found less in practice. Instructional knowledge generally guides the practices but this study found teachers had high status of assessment knowledge but not practices as same ratio in the classroom. Botha (2011) also found practice was not been implemented as the teachers' knowledge as they had.

Social development theory based on Vygotsky (1978) believed on three basic assumptions for the cognitive development out of them there is found associated with the assumption of the zone of proximal development (ZPD) and its process ' Learning through scaffolding'.

Assessment techniques used under the sub-theme 'reflection' shows their learning situation and level of understanding where ZPD can play a vital role to enhance the students' learning level finding. The learning gap of the learner can scaffold through either teacher or peer, or other learning resources that can help to reduce the ZPD area of learners. Therefore, class 
presentation, group discussion, portfolio, quiz competition practiced in the classroom helps to assess learners' ZPD and they can evaluate themselves about their learning status and they can scaffold for the betterment (Morgan \& Skaggs, 2016). But regarding the portfolio, both schools had filled students' results so that they could observe the change in learners' cognitive achievements and can scaffold for the new and necessary knowledge but the learners' behavioral change was found ignored in the portfolio. Teachers supposed students' new way of solving mathematical problems and pasted on journal box was taken as a practice of journal. Creating and exposing a journal encourage learners to come across learning in a "community of practice" (Fenwick, 2001)

Practical Assessment. Practical assessment works for the application of theoretical concepts in simulated/ actual classroom situations. From the observation, students used the learned knowledge in the real field to mathematize the physical context. They learned the concepts, rules, and principles in the classroom from the teachers and they applied to find the area from the field that was found more in community schools than institutional schools. Field trips, project work, experiments, and demonstration of practical skills were the main techniques to be used in this theme.

The institutional school (B) had applied semi-practical situations i-e activities were not conducted on real situation but they were drawn the pictures in copy and measured instead of measuring the real objects.

Constructivist learning theory believes to design the assessment which concerns the process rather than the product (Vygotsky, 1978). The process of knowledge construction is more important than can create active knowledge constructors. Knowledge can be constructed through the interaction of the situation and the experience. The role of the school administration is also very important to create an interactive environment for new knowledge production. If school administration encourages teachers to use diverse evaluation techniques then students would be benefited from permanent learning as well as knowledge transformation from theory to practice. As student-learners involve themselves in the process of cognitive inquiry, they become more active and engaged within each interaction (Binti Pengiran \& Besar, 2018). In this way, students reflect their knowledge as per their understanding, and that learners' understanding fosters selfinvolvement in the learning situations.

Examination/ Test. This technique is used to gauge the competence level in theoretical foundations and content knowledge. During observation, this type of test was practiced as a unit test, terminal examination, and final examination which were mentioned in the school calendar. For this type of assessment, teachers follow the school calendar and it is the most practiced assessment technique. Survey results also showed that $100 \%$ of teachers used this method as a major assessment tool. In this theme, just two assessment techniques were mentioned; terminal examination and oral question. Both techniques were the most practiced techniques for the assessment of mathematical knowledge. For instance, the teacher reviewed the pre-knowledge for the preparation of new content than used oral questions. When the teacher taught the new lesson and tried to evaluate students' understanding then used oral questions during teaching time. In this way, oral question was the most commonly used assessment technique in classroom practice. 
Social interaction is a critical component of constructivist learning theory which embodies certain beliefs and behaviors to be observed and practiced (Fenwick, 2001). Oral questioning in the classroom creates an interactive situation from which the teacher can analyze the students' cognitive level to support their needs. Examination /test reflects the students' knowledge level and scaffolding supports continually to uplift the level of his or her in response to the learner's level of performance. The process of scaffolding does not only produce immediate results but increases the skills for independent problem-solving in the future (Wood, Bruner, \& Ross, 1976). Therefore, if the teacher used the examination/ test also as the students' improvement measuring tool then it works as a formative assessment otherwise summative.

Synthesis/ Analysis. This type of assessment aims to strengthen the theory-practical linkages of classroom teaching, learning, and assessment. Under this assessment theme, there were six techniques lie; analysis of test item, analysis of the result, research paper, role play, dramatization, homework assignment. Out of these six techniques, I found the only analysis of results and homework assignments was in practice. Out of these two techniques, institutional schools had not documented result analysis but teachers said they do it at the last of the academic session. In the case of the community school, there was the documentation of result analysis like genderwise, cast-wise, and achievement-wise result analysis. But both school teachers had used 100\% of the assessment techniques as homework/assignments.

Observation findings are supportive of questionnaire findings given in figure 2. Though teachers had responded as they knew about the analysis of test items, role play, and dramatization, mathematics teachers did not use these methods in assessment practice almost but some teachers had responded in the questionnaire as they use in the classroom. According to the teachers' expression during the interview, both community and institutional (B) school teachers expressed similar narratives as "Techniques needs to be chosen according to the nature of the subject. Science and Social teacher may use role-play and dramatization but for mathematics, we don't feel to use necessarily".

Triangulating the findings of the questionnaire, interview, and the observation, mathematics teachers used the assessment themes accordingly examination/test (Mean $=2.87$ ), Reflection (Mean $=2.71)$, practical assessment $($ Mean $=2.68)$, and at the last position the synthesis/ analysis $($ Mean $=2.43$ ) were in practiced accordingly. Though the formative evaluation plan was not prepared formally either in the school's operational calendar or in professional development, teachers had practiced some techniques for formative assessment so that the minimum practice as 'assessment for learning' had been applied.

\section{Conclusion}

This is a case study within the limited area and the finding of the case study may not be generalized though it reflects the teachers' status of assessment literacy and practice in the classroom. Teachers have enough knowledge to assess the diverse learning of learners but school administrative and national evaluation system are not favorable to applying the different assessment techniques in the classroom because summative evaluation is praised for overall assessment rather formative. Therefore, If the inspirative environment is created by school administration and the closed belief 
towards summative evaluation is broken then teachers are able to practice different assessment techniques to assess the different dimensions of learning of the learners. Hence, it is necessary to change the mindset about the assessment, especially for mathematics from the multiple levels for example Policy level and the level of stakeholders- teachers, students, parents, administrators as well as educational experts and critical analysis.

\section{References}

Binti Pengiran, P. H. S. N., \& Besar, H. (2018). Situated Learning Theory: The Key to Effective Classroom Teaching? HONAI, 1(1).

Botha, J. J. (2011). Exploring mathematical literacy: The relationship between teachers' knowledge and beliefs and their instructional practices. The University of Pretoria,

Buckman, K. (2007). What Counts as Assessment in the 21st Century? Thought \& Action, 29.

Creswell, J. W. (2002). Educational research: Planning, conducting, and evaluating quantitative: Prentice Hall Upper Saddle River, NJ.

Fenwick, T. J. (2001). Experiential Learning: A Theoretical Critique from Five Perspectives. Information Series No. 385.

Gillham, B. (2000). Case study research methods: Bloomsbury Publishing.

Kalajahi, S. A. R., \& Abdullah, A. N. (2016). Assessing assessment literacy and practices among lecturers. Pedagogika, 124(4).

Khaniya, T., Parajuli, T. R., \& Nakarmi, S. S. (2015). Background Study: Curriculum, Textbooks, and Student Assessment and Evaluation Retrieved from http://cdclibrary.org/elibrary/ pages/download.php?ref $=1156 \&$ size $=\&$ ext $=$ pdf $\& \mathrm{k}=\&$ alternative $=-1 \&$ usage $=-$ 1\&usagecomment=

Koellner, K., Jacobs, J., Borko, H., Schneider, C., Pittman, M. E., Eiteljorg, E., . . . Frykholm, J. (2007). The problem-solving cycle: A model to support the development of teachers' professional knowledge. Mathematical thinking and learning, 9(3), 273-303.

Koh, K., DePass, C., \& Steel, S. (2019). Developing Teachers'Assessment Literacy: A Tapestry of Ideas and Inquiries: Brill.

Looney, A., Cumming, J., van Der Kleij, F., \& Harris, K. (2018). Reconceptualizing the role of teachers as assessors: teacher assessment identity. Assessment in Education: Principles, Policy \& Practice, 25(5), 442-467. doi:10.1080/0969594X.2016.1268090.

Marion, S., \& Shepard, L. (2017). Assessment literacy to support competency-based education systems and other deeper learning efforts. Presentation as part of iNACOL's National Leadership Webinar Series.

Mellati, M., \& Khademi, M. (2018). Exploring teachers' assessment literacy: Impact on learners' writing achievements and implications for teacher development. Australian Journal of Teacher Education, 43(6), 1.

Morgan, D., \& Skaggs, P. (2016). Collaboration in the zone of proximal development. Paper presented at the DS 83: Proceedings of the 18th International Conference on Engineering 
and Product Design Education (E \& PDE16), Design Education: Collaboration and Cross-Disciplinarity, Aalborg, Denmark, 8th-9th September 2016.

National Council of Teachers of Mathematics, I., Reston, Va. (1995). Assessment standards for school mathematics: National Council of Teachers of Mathematics, Incorporated.

Niss, M. (1993). Assessment in mathematics education and its effects: An introduction. In Investigations into assessment in mathematics education (pp. 1-30): Springer.

Poudel, L. N., \& Bhattarai, G. P. (2018). Integrating the findings from the National Assessment of Student Achievement into the policy process: An experience from Nepal.

Vygotsky, L. (1978). Social Development Theory (L. Vygotsky). In.

Webb, N. (2002). Assessment literacy in a standards-based urban education setting. Paper presented at the annual meeting of the American Educational Research Association, New Orleans.

Wood, D., Bruner, J. S., \& Ross, G. (1976). The role of tutoring in problem-solving. Journal of child psychology and psychiatry, 17(2), 89-100. 